\title{
Prosopagnosia: Un caso de Meningoencefalitis Viral
}

\author{
Mario Ballesteros García ${ }^{a}$, Patricia Fernández Canoa, Miriam Sánchez Tiembloa,
} Lourdes Fuentes Vázqueza ${ }^{\text {, Juan José Criado Álvareza }}$

\begin{abstract}
a Unidad Docente de Medicina Familiar y Comunitaria. Gerencia de Atención Primaria de Talavera de la Reina. Hospital Nuestra Señora del Prado, Talavera de la Reina (Toledo, España).
\end{abstract}

\section{Correspondencia:}

Juan José Criado-Álvarez, Unidad Docente de Medicina Familiar y Comunitaria, Gerencia de Atención Primaria de Talavera de la Reina, C/ José Luis Gallo n 2 , 45600 - Talavera de la Reina (Toledo). Telf.: 925821509, correo electrónico: jjcriado@sescam.jccm.es

Recibido el 6 de julio de 2009.

Aceptado para su publicación el 20 de septiembre de 2009.

\section{RESUMEN}

La prosopagnosia es un trastorno caracterizado por una incapacidad para reconocer caras conocidas. Su presencia aislada es infrecuente, sobre todo en el caso de meningoencefalitis virales sin otra alteración neuropsiquiátrica.

Palabras clave. Prosopagnosia. Meningoencefalitis.

\section{ABSTRACT}

Prosopagnosia: A case of Viral Meningoencephalitis

Prosopagnosia is a disorder characterised by the inability to recognise known faces. Its presentation alone with no other neuropsychiatric disorder, especially in viral meningoencephalitis, is uncommon. Key words. Prosopagnosia, Meningoencephalitis.

\section{INTRODUCCIÓN}

La sintomatología neurológica aislada constituye un reto diagnóstico para los médicos de urgencias y de atención primaria, debido a la dificultad para enfocar la historia clínica y llegar a realizar un adecuado juicio clínico, así como por la potencial gravedad de los diagnósticos diferenciales posibles ${ }^{1-2}$. La prosopagnosia o incapacidad para reconocer caras conocidas es poco frecuente y suele acompañarse de otras alteraciones del reconocimiento visual o de tipo neurológico ${ }^{3}$.

\section{OBSERVACIONES CLÍNICAS}

Se trata de una mujer de 44 años de edad que acudió al servicio de urgencias por un cuadro de malestar general de 48 horas de evolución, acompañado de ligera sensación de mareo intermitente sin pérdida de conciencia, no presentando sensación de giro de objetos ni cortejo vegetativo. Al inicio del cuadro presentó un único pico febril de $38^{\circ} \mathrm{C}$ autolimitado (1 hora). En la anamnesis un familiar refirió de manera anecdótica que la paciente había confundido a su hijo con su padre y viceversa, no siendo ella consciente del error. La exploración física general fue normal.

En la exploración neurológica la paciente estaba consciente, con leve bradipsiquia, episodios intermitentes de desorientación temporoespacial, prosopagnosia con anosagnosia (había identificado a su padre como su hijo y viceversa, sin ser consciente del déficit), pupilas isocóricas y normorreactivas, pares craneales explorables normales, no presentaba rigidez de nuca ni otros signos meníngeos, fuerza y sensibilidad conservadas y simétricas, reflejos osteotendinosos normales, no presentaba dismetrías ni disdiadococinesias, los signos de Romberg y Barany no eran patológicos, reflejo cutáneo-plantar flexor y la marcha era normal.

La pruebas complementarias fueron normales, incluidos el ECG y la radiología de tórax. EI TAC craneal presentó un sistema ventricular de tamaño, situación y morfología normal, espacios cisternales conservados, no se observaron lesiones focales ni efectos de masa y la distribución de sustancias blanca y gris era normal (figura 1). En el LCR se obtuvieron los siguientes parámetros: glucosa 62 mg/dl, proteínas 122 mg/ 
dl, recuento celular 90 células $/ \mathrm{mm}^{3}$ (95\% linfocitos). En la tinción de GRAM no se observaron microorganismos. El diagnóstico final fue de Meningoencefalitis viral.

En la evolución la paciente ingresó en planta con el diagnóstico de Meningoencefalitis de presumible origen viral, siendo tratada no obstante con antibiótico de amplio espectro, así como con aciclovir hasta que se recibió cultivo negativo, estando en habitación de aislamiento. Además, se realizaron determinaciones analíticas tales como perfil tiroideo y serología completa (VIH, HVB, HBC), resultando cifras normales y negativas, respectivamente. Incidentalmente se encontró en el EEG una discreta lentificación del trazado de fondo sin más anomalías destacables. Tras cinco días recibió el alta pese a persistir discreta cefalea, encontrándose en la actualidad completamente asintomática.

\section{COMENTARIOS}

En el caso que nos ocupa, la paciente presentaba un síntoma muy inespecífico y aislado que podía hacer sospechar una intoxicación o una patología psiquiátrica como primeras opciones, algo que tras disponer de los resultados de las pruebas complementarias y la reevaluación clínica continua en el servicio de Urgencias fue descartado, lo cual nos hace reflexionar sobre la importancia de la información otorgada por familiares y el seguimiento del paciente.

Los primeros casos clínicos de prosopagnosia descritos por Wilbrand datan de 1892 y posteriormente por Bodamer en 1947, siendo infrecuente su hallazgo aislado ${ }^{3}$. Las teorías más aceptadas proponen que deben ser lesiones de tipo bilateral para causar este síntoma. Diversos estudios indican que la percepción de caras está asociada a regiones posteriores del cerebro, sobre en todo en áreas de asociación occipitotemporal derecho $0^{4-5}$. No hay unanimidad en cuanto a criterios de clasificación de los casos de prosopagnosia, pero sí parece evidente que los pacientes tienen distintos grados de afectación en el reconocimiento de caras.

En nuestro caso podemos clasificar a nuestra paciente como una "prosopagnosia discriminativa", ya que tenía una incapacidad para percibir y discriminar caras familiares, sin que se viesen déficits perceptivos para otros estímulos visuales ni agnosia para otros objetos $^{4,6}$. Otros autores al déficit de reconocimiento de caras familiares puro sin otra alteración lo denominan "prosopagnosia asociativa", pero su diagnóstico y frecuencia son extremadamente $\operatorname{raros}^{3,4,7,8}$.

La aparición de síntomas neuropsiquiátricos no es rara en las encefalitis virales, en especial en su fase aguda $^{2}$. Sin embargo, en el $60 \%$ de los casos no se consigue filiar el virus, aunque cada vez son más fre-

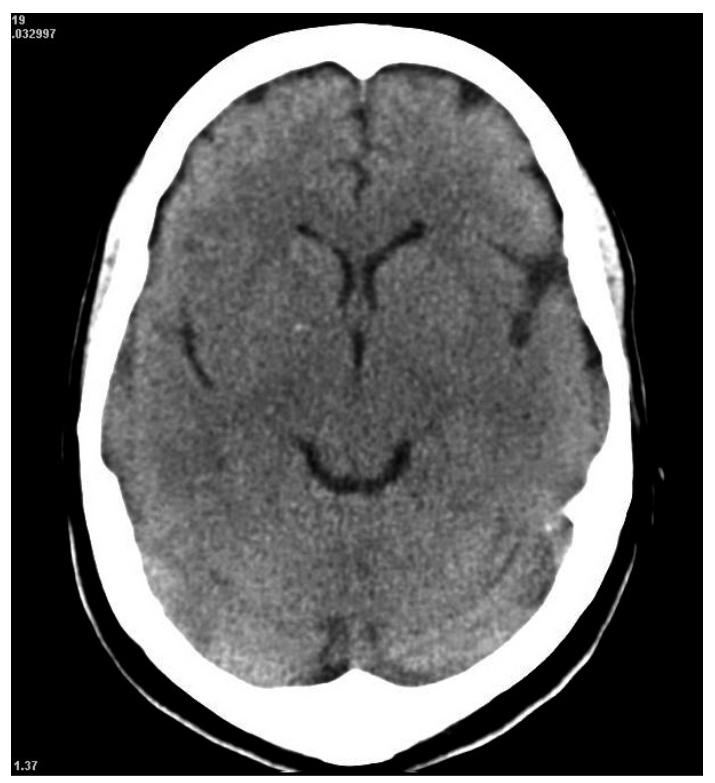

Figura 1. Tomografía Axial Computerizada normal de la paciente 
cuentes virus relacionados con enfermedades emergentes y aquéllas relacionadas con viajes a zonas tropicales ${ }^{1,2,9}$. Un solo síntoma neurológico con un único pico febril aislado y autolimitado durante los días previos a dicho síntoma se manifiesta con poca frecuencia y puede hacernos llegar a infradiagnosticar ciertas patologías que, de ser halladas a tiempo, podrían beneficiarse de un tratamiento que repercutiría tanto en la salud a nivel individual como comunitario.

\section{BIBLIOGRAFÍA}

1. Ramírez-Bermúdez J, Soto-Hernández JL, López-Gómez M, Mendoza Silván M, Colin-Piana R, Campillo-Serrano C. Frecuencia de signos y síntomas neuropsiquiátricos en pacientes con encefalitis viral. Rev Neurol 2005; 41:140-4.

2. Manterola-Cornejo SO, Soto-Hernández JL, Campillo C, Colin R, López-Meza E, Ramírez-Bermúdez J. Trastornos neurop- siquiátricos en pacientes con encefalitis viral. Arch Neurocien (Mex) 2005; 10:245-9.

3. Lopera F. Procesamiento de caras: bases neurológicas, trastornos y evaluación. Rev Neurol 2000; 30:486-90.

4. García-García R, Cacho-Gutiérrez LJ. Prosopagnosia: ¿entidad única o múltiple? Rev Neurol 2004; 38:682-6.

5. Sepúlveda JM, Porta E, Villarejo A, Rodríguez M, Díaz Guzmán J, Ramos A. Prosopagnosia por infarto cerebral derecho unilateral: Estudio de cuatro casos. Neurología 2003; 18:649.

6. Wada Y, Yamamoto T. Selective impairment of facial recognition due to a haematoma restricted to the right fusiform and lateral occipital region. J Neurol Neurosurg Psychiatry 2001; 71:254-7.

7. De Renzi E, Faglioni P, Grossi D, Nichelli P. Aperceptive and associative forms of prosopagnosia. Cortex 1991; 27:213-21.

8. Mendez M, Ghajarnia M. Agnosia for familiar faces and odors in a patient with right temporal lobe dysfunction. Neurology 2001; 57:519-21.

9. Davidson K, Crowcroft N, Ramsay M, Brown D, Andrews N. Viral encephalitis in England, 1989-1998: What did we miss? Emerg Infect Dis 2003; 9:234-40. 